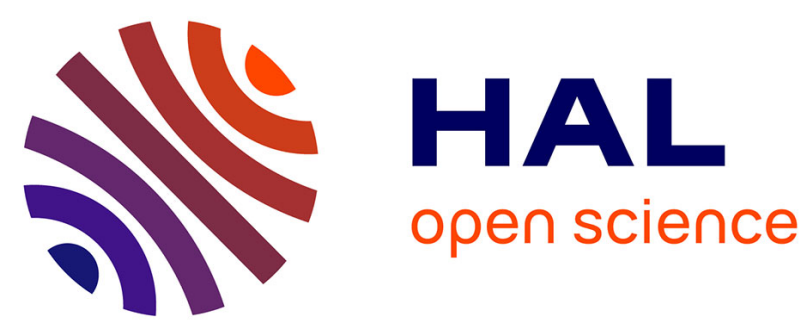

\title{
Evaluation of Alkyl-Ferrocene Monolayers on Carbons for Charge Storage Applications, a Voltammetry and Impedance Spectroscopy Investigation
}

\author{
Yara Aceta, Yann Leroux, Philippe Hapiot
}

\section{- To cite this version:}

Yara Aceta, Yann Leroux, Philippe Hapiot. Evaluation of Alkyl-Ferrocene Monolayers on Carbons for Charge Storage Applications, a Voltammetry and Impedance Spectroscopy Investigation. ChemElectroChem, 2019, 6 (6), pp.1704-1710. 10.1002/celc.201801852 . hal-02115713

HAL Id: hal-02115713

https://hal-univ-rennes1.archives-ouvertes.fr/hal-02115713

Submitted on 8 Jul 2019

HAL is a multi-disciplinary open access archive for the deposit and dissemination of scientific research documents, whether they are published or not. The documents may come from teaching and research institutions in France or abroad, or from public or private research centers.
L'archive ouverte pluridisciplinaire HAL, est destinée au dépôt et à la diffusion de documents scientifiques de niveau recherche, publiés ou non, émanant des établissements d'enseignement et de recherche français ou étrangers, des laboratoires publics ou privés. 


\title{
Evaluation of Alkyl-Ferrocene Monolayer on Carbons for Charge Storage Applications. Voltammetry and Impedance Spectroscopy investigations.
}

\author{
Yara Aceta, Yann R. Leroux and Philippe Hapiot*
}

Univ. Rennes, CNRS, ISCR - UMR 6226, Campus de Beaulieu, F-35000 Rennes, France.

* Corresponding Author: philippe.hapiot@univ-rennes1.fr

\begin{abstract}
Electrochemical properties of functionalized carbons with ferrocene alkyl monolayer were evaluated with different electrolytes and solvents for charge storage applications. Investigations were performed both by cyclic voltammetry and impedance spectroscopy using edge plane pyrolytic graphite (PG) electrodes, being a good example of fragile and porous carbon material. The functionalization method is based on the electrografting of protected aryldiazonium ions that leads after deprotection to the formation of a covalently attached monolayer. In a second step, $\mathrm{C}_{11}$-long chain alkyl ferrocene is attached on the platform. The functionalization considerably increases the charge density by a factor of 5-10 depending on the electrolyte with the advantage that it does not alter the structure of the carbon surface. The grafted layer presents a very fast electron transfer kinetics providing an easy way for increasing the charge density in devices like supercapacitors, the charging time being limited by the resistance of the electrolyte.
\end{abstract}

\section{Introduction.}

Carbon materials are widely considered for charge storage applications notably the electrochemical supercapacitor applications because of their high active surfaces and the numerous possibilities of chemical functionalization. ${ }^{[1,2,3,4,5,6,7,8]}$ Improvements of the charge storage in supercapacitors have been obtained by an adequate choice of the carbon material (See for example ref 4 ) but also by introduction of mineral or organic materials ${ }^{[1-5]}$. In relation with the present work, by the introduction of small redox molecules in carbons materials for improving the characteristics of electrochemical supercapacitors is the subject 
of active researches (See for example the references 9-19 and the references therein). ${ }^{[9,10,11,12,13,14,15,16,17,18,19]}$ In such electrochemical supercapacitor, the charge storage is due both to a "real" electrochemical double layer capacitance (namely movement of ions at the carbon/solution interface) and a faradaic processes. They are often qualified as pseudocapacitors because the charge/discharge process is not purely capacitive. ${ }^{[1,12]}$ The increase of the charge density is therefore due to the additional contributions of faradaic and purely capacitive processes. Concerning the functionalization of carbons by small redox molecules,' the chemical functionalization could be achieved by simple adsorption or chemical grafting but should not alter the double layer capacitance to maximize the synergy between the faradaic and double layer capacitance processes. ${ }^{[12,14,17,20]}$ It means that the initial structure of the carbon material must be kept and that the added monolayer should not block or limit the transport of ions from the solution to the carbon substrate. In this connection, we have developed an electrochemical method that permits the covalent grafting of a monolayer of long alkyl-redox groups on a carbon surface with a controlled spatial arrangement and spacing between alkyl groups. ${ }^{[21,22]}$ Such monolayers could be compared to what is obtained with long chain alkyl-thiol that forms self-assembled monolayer on gold surface, but for a monolayer that is covalently bonded on the carbon surface. ${ }^{[21,22]}$ Alkyl-ferrocene-terminated monolayers on carbon exhibit fast charge transport from the substrate to the redox moieties. As interest for the present work, the alkyl layer on carbon is flexible and could be made porous allowing the mass transport from solution to the substrate through the pinholes between the chemical groups. ${ }^{[23,24]}$

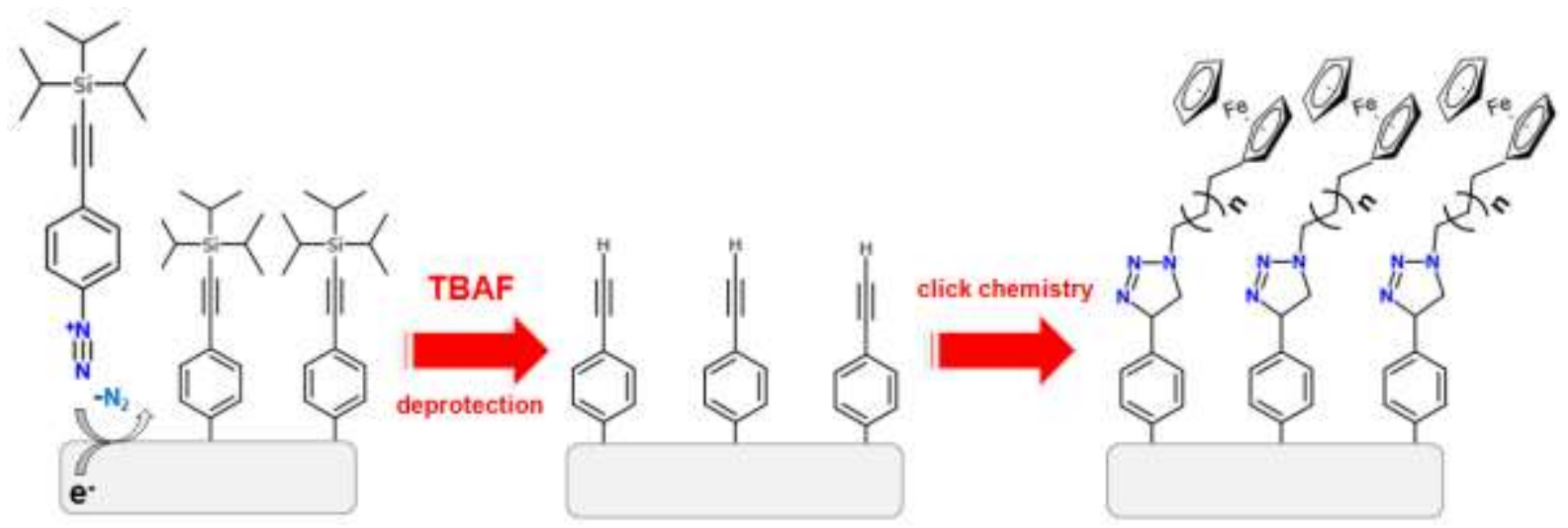

Scheme 1. General process for modifying the carbon materials. On the right, the resulting (11azidoundecyl)ferrocene monolayer, where $n=9$, covalently attached to a carbon substrate.

In this paper, we have examined the possibility of such alkyl redox monolayer for improving the charge densities and response time in active carbon materials in view of charge storage 
applications. The functionalization is based on the electrografting of aryldiazonium ions that leads upon electrochemical reduction to the formation of phenyl radicals that will attach on the electrode surface. ${ }^{[7,8,23]}$ We used a protected ethynyl-aryldiazonium salt bearing a bulky tri(alkyl)silyl group. This limits the grafting on the carbon surface to a single layer and protects the ethynyl functional group during the electrochemical grafting. After deprotection, a single monolayer of ethynyl-phenyl layer covalently attached to the carbon surface is obtained. In a second step, this layer is used as a molecular platform to attach an electroactive group with a dense coverage and good organization of the layer. ${ }^{[21,22,23]}$

As illustrated on Scheme 1, the distance between the redox groups is finally controlled by the size of the protecting group that leaves a sort of footprint in the layer after deprotection. We used a bulky tri(isopropyl)silyl group that has been shown to be a compromise for obtaining a dense monolayer but sufficiently porous for a good mass transport to the substrate ${ }^{[23,24]}$ Concerning the choice of the redox group, in most studies reported in the literature, investigators generally favor the use of multi-electronic redox couples like quinones or catechols because each redox unit could store more than one charge per redox units. ${ }^{[14,16]}$ However, this advantage is counterbalanced by the fact that they are not real $2 \mathrm{e}^{-}$systems but $2 \mathrm{e}^{-}+2 \mathrm{H}^{+}$redox couples (or $2 \mathrm{e}^{-}+1 \mathrm{H}^{+}$at high $\mathrm{pH}$ ). They are only reversible in defined conditions of solvent/electrolyte (aqueous solvent), require a specific range of $\mathrm{pH}$ to be electrochemically stable and the global charge transfer kinetics remain generally slower than for a true outer-sphere redox couple. ${ }^{[25]}$ We tried a different type of redox couple, the ferrocene/ferrocenium couple that presents a vey fast charge transfer kinetics with an outersphere character. This is an important characteristic for this study as their fast electrochemical behavior is compatible with numerous solvents or electrolytes. The $\mathrm{C}_{11 \text { - }}$ alkyl-ferrocene was grafted on an edge planes pyrolytic graphite surface (PG electrode) but the approach is usable on many different carbon materials, as glassy carbon, graphite or carbon nanotubes. ${ }^{[7,8]} \mathrm{PG}$ electrodes are highly porous, with a pore-size distribution ranging from the micro to nanometric level; they allow detailed kinetics investigations and are commonly used for preparing enzymatic sensors since their high active surface. ${ }^{[26]}$

We have examined the properties of the modified PG electrode focusing on the increase of the pseudo-capacitance upon modification and to the influence of the electrolyte/solvent on charge processes and capacity. The electrode characteristics were simultaneously investigated by cyclic voltammetry (CV) and electrochemical impedance spectroscopy (EIS). Such combined approach has shown its interest in the investigations of modified carbon material. (See for examples references $2,17,5$ ) or of redox-active monolayers. ${ }^{[27]}$ Cyclic voltammetry 
provides information corresponding to the integrated charges. If such quantities are less detailed information than the corresponding differential data extracted by EIS, they are also closer to the charge storage density required by users in a real applications. ${ }^{[2,16]}$

\section{Experimental.}

Chemicals and reagents. Commercially available reagents were used as received without further purification. 4-(tri(isopropylsilyl)ethynyl) benzenediazonium tetrafluoroborate (TIPSEth- $\mathrm{ArN}_{2}$ ) was synthesized according with the literature. ${ }^{[21]}$ The (11-azidoundecyl)ferrocene was synthesized following a previously published procedure. ${ }^{[28]}$ Tetrabutylammonium fluoride (TBAF) and ferrocene were purchased from Alfa Aesar. Acetonitrile (HPLC grade), dichloromethane (HPLC grade) and dimethylformamide (analytical grade) were purchased from Fisher Scientific UK, ethanol (98\%, absolute anhydrous) from Carlo Erba Reagents and propylene carbonate $(99.7 \%$, anhydrous) from Sigma-Aldrich. Electrolytes: tetrabutylammonium hexafluorophosphate $(>99 \%$, electrochemical analysis) and lithium perchlorate (>98\%) from Sigma-Aldrich, and potassium hexafluorophosphate $(99 \%$, extra pure) from ACROS Organics. Ferrocenemethanol (97\%) used as standard was purchased from Sigma-Aldrich. Ultrapure water $(18.2 \mathrm{M} \Omega-\mathrm{cm})$ was used for the electrolyte aqueous solutions.

Electrochemical setup and procedures. Cyclic voltammetry and impedance measurements were performed with an Autolab potentiostat PGSTAT302N equipped with an ADC10M and a FRA2 modules; a conventional three-electrode setup was used, comprising the modified substrate as working electrode, a platinum foil as the auxiliary electrode, and a saturated calomel electrode (SCE) as reference. All potentials were standardized using ferrocenemethanol/ferroceniummethanol couple as an internal standard, which was added into the electrolyte solutions at the end of each experiment. Edge plane pyrolytic graphite electrodes (PGEs) were purchased from IJ Cambria as 3-mm diameter disks (geometrical surface $=0.071 \mathrm{~cm}^{2}$ ). The electrodes were polished successively with 2400 and 4000 silicon carbide grinding paper and ultrapure water, and thoroughly rinsed with ultrapure water and acetone. The electrode-surface modification was performed as previously reported by grafting of the tri(isopropylsilyl)ethynylbenzene diazonium salt, followed by the deprotection of the ethynyl group and its functionalization by click chemistry with (11azidoundecyl)ferrocene. This procedure led to a well-nanostructured (11-azidoundecyl) ferrocene-terminated monolayer. ${ }^{[22,23]}$ 
Prior to EIS analysis, cyclic voltammetry plots of modified surfaces were acquired at different scan rates in each electrolyte solution to determine the peak potential (faradaic process) and to compare the different methodologies used for determining the capacitance of an equivalent system. ${ }^{[2,17]}$ The ac frequencies for impedance experiments ranged from $10 \mathrm{kHz}$ to $0.01 \mathrm{~Hz}$, with an amplitude of $\pm 10 \mathrm{mV}$. Lissajous curves were monitored at each frequency in order to ensure that no changes in the linearity of the circuit occur during the experiment.

Data Treatment. Experimental data were fitted using Origin 7.5 (Microcal Software Inc.).

\section{Results and discussions.}

As depicted in Scheme 1, the pyrolytic carbon electrodes were modified by electrografting of 4-(tri(isopropylsilyl)ethynyl) benzenediazonium tetrafluoroborate (TIPS-Eth-ArN ${ }_{2}$ ). After deprotection, the ethynyl layer was post-functionalized by "Click Chemistry" with (11azidoundecyl)ferrocene following the previously published procedure. ${ }^{[24]}$ At this point, we obtained a dense layer of ferrocenyl moieties that are linked to the carbon material with a

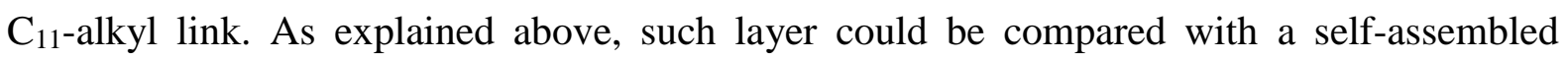
monolayer (SAM) of alkylthiol on gold surface but with the difference that the substrate is carbon and that the link is attached on the surface by covalent bond. It allows a distance control between the functional groups and the density of the layer. The cyclic voltammograms on Figure 1a shows the response of the modified electrode in dichloromethane $\left(\mathrm{CH}_{2} \mathrm{Cl}_{2}\right)$ containing $10^{-1} \mathrm{~mol} \mathrm{~L}^{-1}$ tetrabutylammonium hexafluorophosphate $\left(n \mathrm{Bu}_{4} \mathrm{NPF}_{6}\right)$. A reversible electrochemical system is visible that corresponds to the reversible oxidation of the grafted ferrocene groups. The peak potential varies linearly with the scan rate in agreement with a grafted electrochemical system. ${ }^{[29]}$ Considering the geometrical surface area, from the integration of the faradaic peak current, we derived a surface coverage around $1.210^{-9} \mathrm{~mol} \mathrm{~cm}^{-2}$. This value is about 10 times higher than the value expected for a monolayer but on a flat surface ${ }^{[22,23]}$ and our estimation does not take into account the large active surface area of the PG electrode. (See the AFM images on Figure S3 in the supplementary part). This value is in agreement with reported coverage on PG electrode ${ }^{\text {[26] }}$ and confirms that a dense layer is indeed immobilized on the carbon surface.

The corresponding EIS responses of the electrode are shown on Figure 1c-d before and after carbon modification when the solvent is $\mathrm{CH}_{2} \mathrm{Cl}_{2}$. We performed these experiments at two characteristics potentials that are marked by the lines on the CV: $-0.08 \mathrm{~V}$ and $0.30 \mathrm{~V} v s$ the $\mathrm{FcMeOH} / \mathrm{FcMeOH}^{+}$couple. 

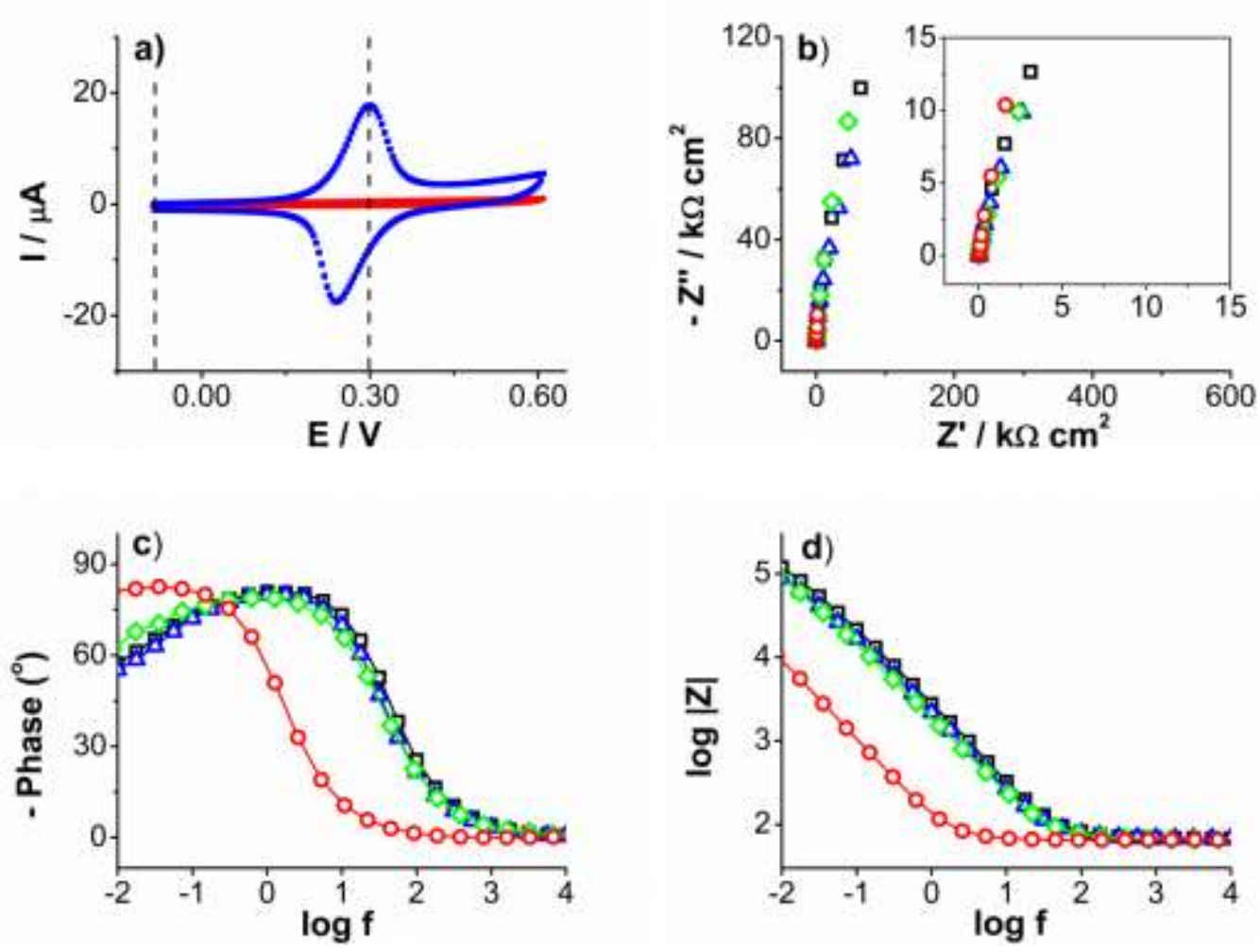

Figure 1. (a) Current versus potential plots of a bare $(\bullet)$ and a $\mathrm{FcC}_{11}$ monolayer modified ( $\square$ ) pyrolytic graphite (PG) electrode in $\mathrm{CH}_{2} \mathrm{Cl}_{2}+0.1$ mol L-1 $n \mathrm{Bu}_{4} \mathrm{NPF}_{6}$ solution at $0.1 \mathrm{~V} \mathrm{~s}^{-1}$. Two vertical dash lines mark the two different fixed potentials at which EIS data were acquired, - $0.08 \mathrm{~V}$ and $0.30 \mathrm{~V}$. (b) Nyquist and (c,d) Bode diagrams of a bare $(\square, \Delta$ ) and a $\mathrm{FcC}_{11}$ monolayer modified $(\diamond, \circ) \mathrm{PG}$ electrode in $\mathrm{CH}_{2} \mathrm{Cl}_{2}+0.1 \mathrm{~mol} \mathrm{~L}^{-1} n \mathrm{Bu}_{4} \mathrm{NPF}_{6}$ solution at - $0.08 \mathrm{~V}(\square, \diamond)$ and $0.30 \mathrm{~V}(\Delta, \circ)$. All potentials are reported versus $\mathrm{FcMeOH} / \mathrm{FcMeOH}^{+}$ couple used as internal standard.

As observed on the EIS spectra at $-0.08 \mathrm{~V}$ vs $\mathrm{FcMeOH} / \mathrm{FcMeOH}^{+}$, the responses do not totally correspond to a pure capacitance behavior even for the bare PG electrode. (For a pure capacitance in an $\mathrm{RC}$ scheme, the phase-angle changes from $90^{\circ}$ at low frequencies to $0^{\circ}$ at high frequencies). ${ }^{[30]}$ This is visible on the phase variation at low frequencies or on the corresponding Nyquist plot showing the variation of the imaginary part Z" as function of the real part Z' of the complex impedance. This observation is common for carbon electrodes and is generally ascribed to the heterogeneity of the surface both in terms of topological structures and chemical groups on the surfaces. ${ }^{[17,31]}$ As shown on the AFM images (Figure S3), edge planes pyrolytic graphite presents numerous fissures and pores and the electrode behaves as a collection of impedances with different values and time constants leading to the response observed in EIS. It is important to note that there is no major change in the EIS response of the pyrolytic edge planes carbon after the functionalization of the electrode at - 
$0.08 \mathrm{~V}$, compare $(\square)$ and $(\diamond)$. One could just observe that the phase is slightly more constant at low frequency and closer to what is expected for a pure capacitor. This shows that the grafting does not modify the capacitive contribution and that the main geometric structure of the surface is kept. This observation falls in lines with the AFM images of Figure S3. Images are similar before and after grafting indicating that there is no considerable change in the topology or roughness of the surface. The small differences in the EIS could be ascribed to a chemical homogenization due to the modification of the surface groups by the phenyl derivatives. $^{[22]}$ Considering a simplified impedance RC circuit, we derive the apparent resistance and capacitance of our electrodes as $\mathrm{R}=69$ and $66 \Omega \mathrm{cm}^{2}$, and $\mathrm{C}=52$ and $73 \mu \mathrm{F}$ $\mathrm{cm}^{-2}$ for the bare and functionalized pyrolytic graphite electrodes, respectively.

When the same experiments are performed at $0.30 \mathrm{~V}$ vs $\mathrm{FcMeOH} / \mathrm{FcMeOH}^{+}$, no change in the EIS spectra are observed for the bare pyrolytic graphite electrode, whereas on the functionalized electrode at this potential, i.e. when the ferrocenyl groups are oxidized, a large decrease of the impedance is visible. See Table 1 and compare $(\Delta)$ and $(\circ)$. To quantify such variation, instead of the raw impedance data, it is convenient to treat the super-capacitance of the modified electrode as an apparent capacitance that would contain all the non-capacitive terms. $^{[2,17,32]}$ The apparent capacitance $C(\omega)$ is thus simply derived from the complex impedance as $Z(\omega)=(j \omega C(\omega))^{-1}$. For a real electrode, its apparent capacitance contains both a real and an imaginary parts: $C(\omega)=C^{\prime}(\omega)-j C^{\prime \prime}(\omega)$. (For a pure capacitance, the imaginary part is equal to zero). The imaginary part shows the non-ideality of the system in terms of complex capacitance. The real (1) and imaginary (2) parts could be derived from the complex impedance by the following transformations: ${ }^{[2]}$

$$
\begin{aligned}
& C^{\prime}(\omega)=\frac{-Z^{\prime \prime}(\omega)}{\omega|Z(\omega)|^{2}} \\
& C^{\prime \prime}(\omega)=\frac{Z^{\prime}(\omega)}{\omega|Z(\omega)|^{2}}
\end{aligned}
$$

Variations of the apparent capacitance are shown on Figure 2 for the two applied potentials. As first observation, a large increase of the real part capacitance occurs at frequency around 2 $\mathrm{Hz}$ when the ferrocenyl moieties are oxidized (i.e. at $\mathrm{E}=0.30 \mathrm{~V}$ ). On the contrary, the nonfaradic process (at $\mathrm{E}=-0.08 \mathrm{~V}$ ) tends to be less frequency-dependent but still shows a small increase around $30 \mathrm{~Hz}$. 

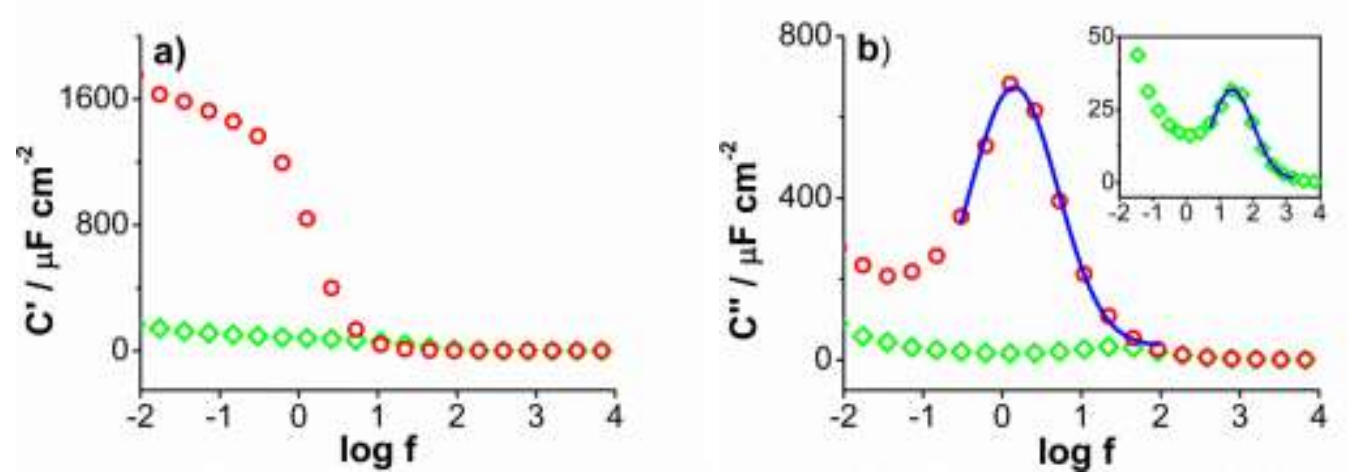

Figure 2. Evolution of the (a) real and (b) complex capacitances versus frequency for $\mathrm{FcC}_{11}$ monolayer on a PG electrode in $\mathrm{CH}_{2} \mathrm{Cl}_{2}+0.1 \mathrm{~mol} \mathrm{~L}^{-1} n \mathrm{Bu}_{4} \mathrm{NPF}_{6}$ at two different fixed potential, $-0.08 \mathrm{~V}(\diamond)$ and $0.30 \mathrm{~V}(\circ) \mathrm{vs} \mathrm{FcMeOH} / \mathrm{FcMeOH}^{+}$.

Basically, the system oscillates between two states; it shows a capacitor-like behavior at low frequencies and a resistor at high frequencies, in between, it behaves like an $\mathrm{R}-\mathrm{C}$ circuit. Figure $2 \mathrm{~b}$ presents the evolution of the complex capacitance vs frequency; the complex capacitance goes through a maximum at the frequency point defined as characteristic frequency, $\omega(\omega=1 / \mathrm{RC})$ or time constant, $\tau \quad(\tau=\mathrm{RC}) \cdot{ }^{[1,33]}$ Results of Figure 2 are very similar to the EIS spectra reported for a well-organized ferrocene-undecanethiol film deposited on gold (frequency and half peak width) ${ }^{[32]}$ confirming the analogy of the obtained layer on pyrolytic graphite and a self-assembled monolayer on gold. As $C(\omega)$ is a complex function, it could also be presented as a Nyquist plot by analogy with what is done for the impedance $Z(\omega)$. Such plots provide a better estimation of the capacitance by a simple fitting of the equivalently generated Nyquist plot with a semi-circle variation.
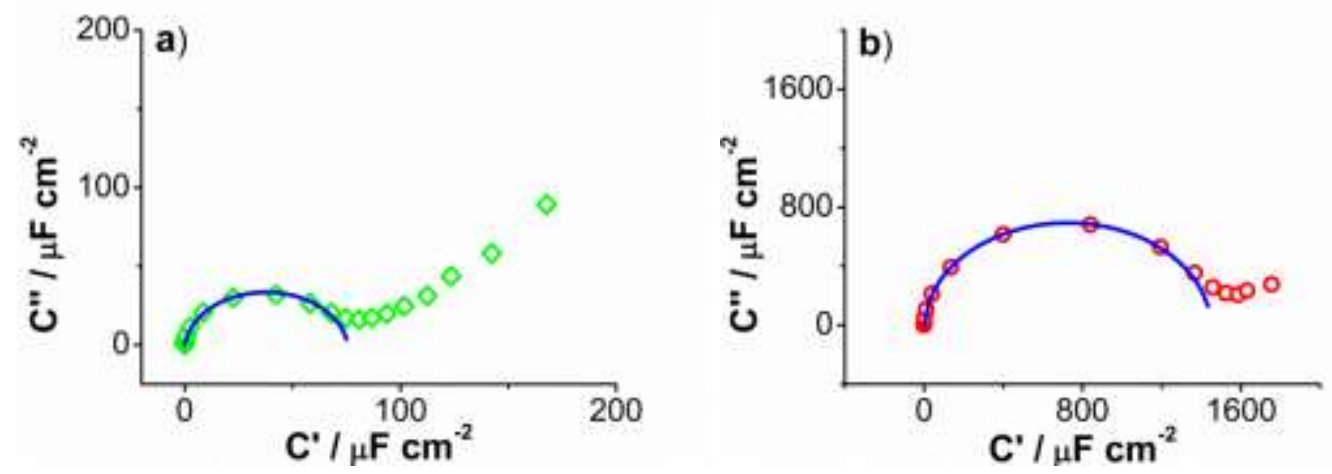

Figure 3. Nyquist capacitive plots of the $\mathrm{FcC}_{11}$ monolayer on a $\mathrm{PG}$ electrode in a $\mathrm{CH}_{2} \mathrm{Cl}_{2}+$ $0.1 \mathrm{~mol} \mathrm{~L}^{-1} n \mathrm{Bu}_{4} \mathrm{NPF}_{6}$ solution at (a) $\mathrm{E}=-0.08 \mathrm{~V}$ and (b) $0.30 \mathrm{~V}$ vs $\mathrm{FcMeOH} / \mathrm{FcMeOH}^{+}$. Lines correspond to semi-circle curve-fittings. 
Figure 3 shows the corresponding Nyquist capacitive plots, without (Figure 3a) and with the contribution of the faradaic process to the capacitance (Figure 3b). The value of capacitance is thus given by the diameter of the semicircle of the Nyquist capacitive spectrum and is estimated by a semi-circle fitting as seen on the full lines. From these experiments, we derived a capacitance of $73 \mu \mathrm{F} \mathrm{cm} \mathrm{cm}^{-2}$ at $-0.08 \mathrm{~V}$ with a characteristic time $\tau=48 \mathrm{~ms}$, and a much higher capacitance of $1475 \mu \mathrm{F} \mathrm{cm}^{-2}$ at $+0.30 \mathrm{~V}$ and a corresponding characteristic time of $\tau=97 \mathrm{~ms}$. $R$ is obtained from the magnitude of $Z$ at high frequency (see Figure 1d) and does not appreciably change with or without the faradic contribution $\left(\mathrm{R}=66 \Omega \mathrm{cm}^{2}\right)$. In other words, $\tau$ varies linearly with the apparent capacitance measured at $-0.08 \mathrm{~V}$ and +0.30 $\mathrm{V}$ respectively. It means that in this electrolyte, the charging time of the modified electrode is indeed controlled by the resistance at the carbon materials /solution interface and not by the electron transfers kinetics to the ferrocene moieties that is much faster, and thus that energy efficiency at short times depends on the electrolyte. This conclusion falls in line with fast electrochemical measurement concerning long alkyl-ferrocene-thiol layer on gold for which the rate constants of the electron transfer are in the $10^{6} \mathrm{~s}^{-1}$ range. ${ }^{[34]}$
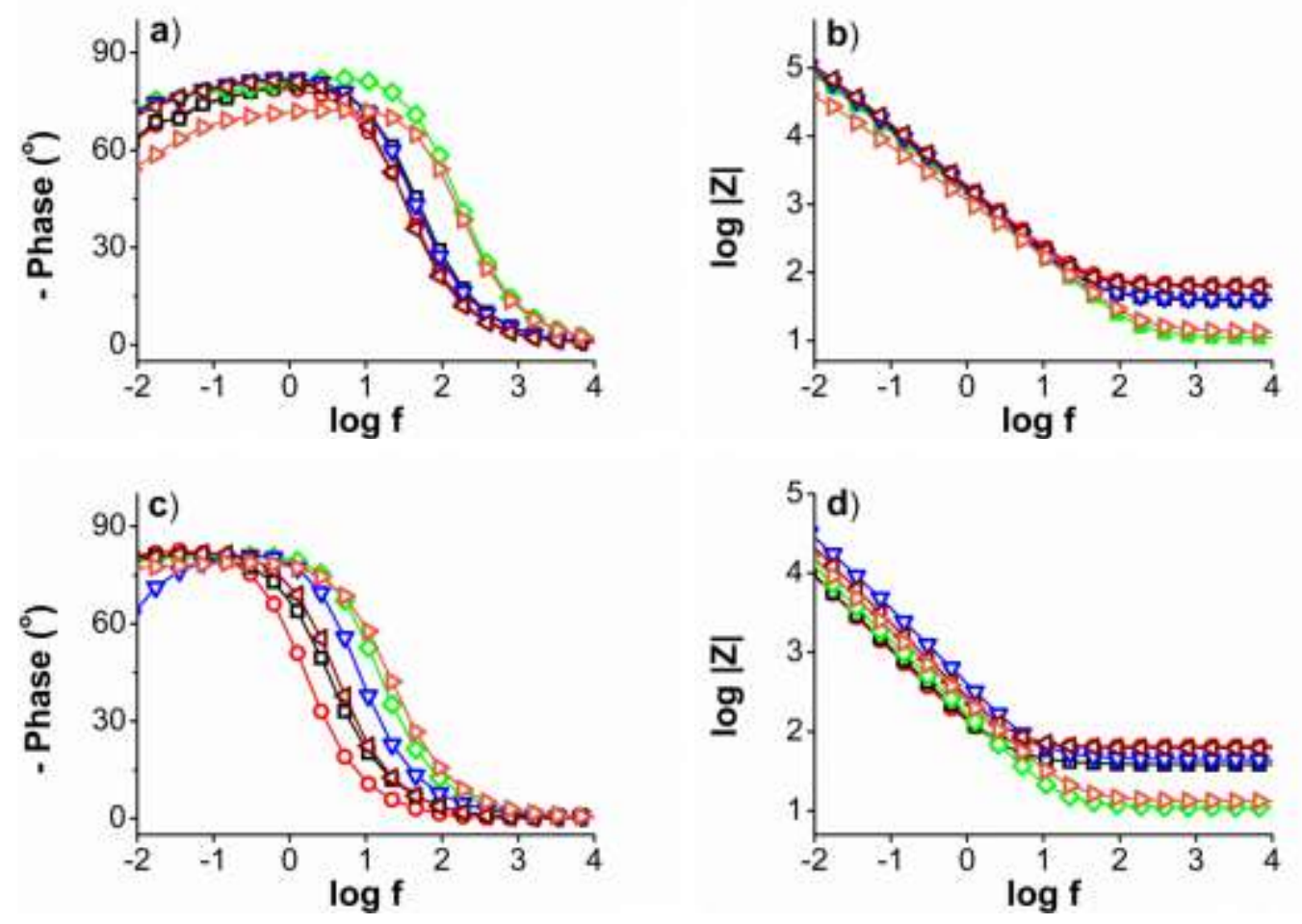

Figure 4. (a,c) Phase-angle and (b,d) $\log |\mathrm{Z}|$ versus $\log$ frequency of the $\mathrm{FcC}_{11}$ monolayer on a PG in $(\circ) \mathrm{CH}_{2} \mathrm{Cl}_{2},(\diamond) \mathrm{ACN},(\nabla) \mathrm{DMSO}$ and $(\triangleleft) \mathrm{PC}+0.1 \mathrm{~mol} \mathrm{~L}^{-1} n \mathrm{Bu}_{4} \mathrm{NPF}_{6}$, in ( $\left.\square\right)$ $\mathrm{EtOH}+0.1 \mathrm{~mol} \mathrm{~L}^{-1} \mathrm{LiClO}_{4}$ and in $(\triangleright)$ water $+0.1 \mathrm{~mol} \mathrm{~L}^{-1} \mathrm{KPF}_{6}$ at $(\mathrm{a}, \mathrm{b})$ an applied potential where there is no faradic contribution and (c,d) at an applied potential where the ferrocenyl moieties are oxidized. 
To get more insights on this limitation due to the media, we performed detailed electrochemical studies of the functionalized electrode in different common electrolytes. The impedances variations are shown on Figure 4 and the derived capacitances and characteristics times on Table 1 for the system $\mathrm{FcC}_{11}-\mathrm{PG}$ electrode in different $0.1 \mathrm{~mol} \mathrm{~L}^{-1}$ electrolytes. For all media, the modified electrode/electrolyte behaves as a RC circuit. Similarly to the previous data obtained when the modified electrode is studied in $\mathrm{CH}_{2} \mathrm{Cl}_{2}, \mathrm{R}$ is not affected by the presence of the faradaic process indicating that the charging time is controlled by the ohmic drop and not by the charge transfer kinetics. It is also noticeable that besides the variations of $\mathrm{R}$, the apparent capacitance when the faradaic process is involved changes a lot with the electrolyte. In a practical view, ethanol or acetonitrile (ACN) could be seen as the best compromise between the largest capacitance and the shortest charging times. In these electrolytes, the capacitance is only a bit smaller, no more than $30 \%$ smaller than in $\mathrm{CH}_{2} \mathrm{Cl}_{2}$, but with a much lower charging time. (Around 10 times faster) If water is required for the application, the modification is still valuable as it permits a large increase of the charge density with a short response time.

Table 1. Electrochemical characteristics of the PG electrodes.

\begin{tabular}{cccccccc}
\hline Applied Potential / Electrolyte & & $\mathrm{CH}_{2} \mathrm{Cl}_{2}$ & $\mathrm{EtOH}$ & $\mathrm{ACN}$ & $\mathrm{DMSO}$ & $\mathrm{PC}$ & Water \\
\hline Modified electrode & $\mathrm{R} / \Omega \mathrm{cm}^{2}$ & 66 & 39 & 11 & 41 & 63 & 14 \\
without faradaic & $\tau / \mathrm{s}$ & 0.0048 & 0.0034 & 0.0010 & 0.0036 & 0.0050 & 0.0011 \\
& $\mathrm{C} / \mu \mathrm{F} \mathrm{cm} \mathrm{cm}^{-2}$ & 73 & 86 & 88 & 88 & 80 & 80 \\
\hline Modified electrode & $\mathrm{R} / \Omega \mathrm{cm}^{2}$ & 65 & 39 & 11 & 45 & 62 & 13 \\
with faradaic at peak potential & $\tau / \mathrm{s}$ & 0.097 & 0.049 & 0.010 & 0.017 & 0.039 & 0.008 \\
& $\mathrm{C} / \mu \mathrm{F} \mathrm{cm} \mathrm{cm}^{-2}$ & 1480 & 1270 & 930 & 410 & 610 & 590 \\
\hline From Cyclic Voltammetry & & & & & & & \\
$\quad$ (with faradaic) & $\mathrm{C} / \mu \mathrm{F} \mathrm{cm} \mathrm{cm}^{-2}$ & 570 & 570 & 360 & 220 & 310 & 320 \\
$\Delta E=0.7 \mathrm{~V}$ (from -0.1 to 0.6 V) & & & & & & & \\
\hline
\end{tabular}

Finally, it is interesting to compare the different methodologies for investigating the modified electrode and then discuss the efficiency of $\mathrm{FcC}_{11}$ monolayer for improving the pseudocapacity of the material in view of literature data where small redox molecules are used for improving the pseudo-capacitance. In the case of an interfacial charging process in which the capacitance is not constant over a given voltage window, the global capacitance could be 
estimated from cyclic voltammetry data as it was previously proposed (see the supporting information section for details about the calculations). ${ }^{[12]}$ The effective capacitance is calculated from the integral of the curve current $v s$ time that is the area under the curve that corresponds with the charge stored, and the charge is simply divided by the voltage variation to derive the capacitance. Integration was made on the whole scan from -0.1 to $0.6 \mathrm{~V} v s$ the $\mathrm{FcMeOH} / \mathrm{FcMeOH}^{+}$couple $(\Delta \mathrm{E}=0.7 \mathrm{~V})$. This value provides an efficient storage capability of the modified carbon. The derived data are reported in Table 1 and are obviously lower than the values derived by EIS but show the interest of the modifications that indeed increase the effective charge density storage.

Table 2. Example of Capacitances Variations before and after functionalization calculated from CV.

\begin{tabular}{|c|c|c|c|c|c|}
\hline $\begin{array}{c}\text { Carbon based } \\
\text { materials }\end{array}$ & Modifiers & $\begin{array}{l}\text { Functionalization } \\
\text { technique }\end{array}$ & Variation $^{\mathrm{a}}$ & $\tau / \mathrm{s}$ & Ref \\
\hline Carbon fabric & Anthraquinone & $\begin{array}{l}\text { Diazonium } \\
\text { grafting }\end{array}$ & 1.4 & - & 9 \\
\hline $\begin{array}{l}\text { Hierarchical porous } \\
\text { carbon nanotubes }\end{array}$ & Anthraquinone & $\begin{array}{l}\text { Solvothermal } \\
\text { reaction }\end{array}$ & 2.3 & - & 14 \\
\hline $\begin{array}{c}\text { Carbon Black Pearl } \\
2000\end{array}$ & $\begin{array}{c}\text { Anthraquinone } \\
\text { 9,10-Phenanthrenequinone }\end{array}$ & $\begin{array}{l}\text { Diazonium } \\
\text { grafting }\end{array}$ & $\begin{array}{l}2.0 \\
2.5\end{array}$ & - & $10,15,16$ \\
\hline $\begin{array}{l}\text { Activated carbon } \\
\quad \text { (Norit S-50) }\end{array}$ & Catechol & $\begin{array}{l}\text { Diazonium } \\
\text { grafting }\end{array}$ & $1.8^{\mathrm{b}}$ & 3 & 17 \\
\hline $\begin{array}{l}\text { Porous carbon (from } \\
\text { carrots) }\end{array}$ & Anthraquinone & $\begin{array}{l}\text { Solvothermal } \\
\text { reaction }\end{array}$ & 1.5 & - & 18 \\
\hline Carbon-onion & $\begin{array}{c}\text { 4,5-Pyrenedione } \\
\text { 9,10-phenanthrenequinone }\end{array}$ & $\begin{array}{l}\text { Adsorption } \\
\text { Adsorption }\end{array}$ & $\begin{array}{c}6.8 \\
12.6\end{array}$ & - & 13 \\
\hline Pyrolytic graphite & Alkyl-ferrocene Monolayer & $\begin{array}{l}\text { Diazonium } \\
\text { grafting }\end{array}$ & 10.9 & 0.1 & $\begin{array}{l}\text { This } \\
\text { work }\end{array}$ \\
\hline
\end{tabular}

${ }^{a}$ Variations of the total pseudo-capacitance. ${ }^{b}$ From integration of CV on Fig 4.

The increase of the pseudo-capacitance before and after the modification, as defined above, is a simple way to evaluate the efficiency of $\mathrm{FcC}_{11}$ monolayer for improving the charge density and make comparisons with literature data. ${ }^{[10,18]}$ Table 2 listed some illustrative data reported in the literature about the pseudo-capacitance variation of carbon materials after introduction of small redox molecules. The pseudo-capacitances of porous carbon materials functionalized with quinone and catechol derivatives using the reduction of aryl diazonium salts increase by around 2-2.5 depending on the carbons and the quinones. We found one example in the literature that shows a huge increase in the pseudo-capacitance up to 12.6 but with a special carbon material: carbon-onions. They were functionalized by the adsorption of 9,10- 
phenanthrenequinone and data reported in $1 \mathrm{~mol} \mathrm{~L}^{-1} \mathrm{H}_{2} \mathrm{SO}_{4}$ aqueous solution. ${ }^{[13]} \mathrm{By}$ comparison, after grafting of the $\mathrm{FcC}_{11}$ monolayer on $\mathrm{PG}$ and optimization of the electrolyte/solvent, we observe an increase up to 10.9 of the pseudo-capacitance in $\mathrm{CH}_{2} \mathrm{Cl}_{2}$. Our value is comparable to those reported for the functionalized carbo-onions by a bielectronic redox couple, as the oxidation of ferrocene is only mono-electronic. Unfortunately, the characteristic time constants are rarely reported in these examples but could be of high importance for designing fast devices. Such characteristic RC times constant have been calculated to be as $3.0 \mathrm{~s}$ for porous carbon materials functionalized by catechol redox moieties in aqueous media that could be compared to $97 \mathrm{~ms}$ in $\mathrm{CH}_{2} \mathrm{Cl}_{2}$ down to $10 \mathrm{~ms}$ in $\mathrm{ACN}$ in our case. It is also important to note that the functionalization of carbon is often accompanied by a decrease of the double capacitance of the carbon materials especially for high coverage or loading of small redox, which is not observed with the $\mathrm{FcC}_{11}$ monolayer. ${ }^{[15,20]}$

The comparative large increase obtained with alkyl-ferrocene monolayer arises from the structure and the electrochemical characteristics of alkyl-ferrocene but also because such monolayer is compatible with a large choice of electrolytes and solvents. Indeed as seen on Table 1, the faradaic pseudo-capacitance in water is around half of those in $\mathrm{CH}_{2} \mathrm{Cl}_{2}$ or $\mathrm{MeOH}$ showing the need of an optimization of the solvent. At this stage, the origin of this variation of the pseudo-capacitance with the solvent is not totally clear, but it is noticeable that the variation concerns mainly the faradaic process as the double layer does change in a much lower extend. We have not made an exhaustive study as function of the ions of the supporting electrolyte, but we have not observed a clear correlation with some characteristic of the salt like its ion size. There are little studies in the literature about this effect, but by analogy with SAMs on gold, we could ascribe it to changes of the alkyl layer structure upon oxidation and concerted ion pairing, both depending of the dielectric constant of the solvent. ${ }^{[35,36]}$

\section{Conclusion.}

As reported in the literature, the introduction of small redox molecules on a carbon capacitor is a convenient way for improving the global charge density of these materials. In this work, we show all the interest of introducing them in an organized manner with the example of long chain alkyl-ferrocene monolayer that presents a fast charge transfer in presence of many different solvents. After modification and optimization of the solvent, we observed a considerable increase of the charge density storage by a ratio up to 10 which is higher than most of the reports of literature. Of course, such results still need to be tested with other 
carbon materials but they already show the potential interest of such monolayer in charge storage application.

As for a "classical" capacitance, the characteristic time of the layer depends on the electrolyte, as the charge transfer kinetics from the carbon to the active alkyl-ferrocene moiety is very fast and not a limiting factor. Moreover, we highlight the importance of the solvent not only for the RC time but also for maximizing the value of the faradaic charge. The basic reasons responsible of this effect are under investigations but other electrolytes could probably permit a fast charge associated with a large charge density.

Because of the versatility of the carbon modification process, similar alkyl-redox monolayers could be considered for the modification of many different types of nano-structured carbon as those presenting a large specific surface and controlled porosity. Redox groups other than ferrocene, as those presenting higher electronic stoichiometry could also been used but at the condition that their global charge transfer kinetics remains fast and allows a large choice of solvents.

\section{Supplementary Material Section.}

A supplementary section presents details about the calculations and data in the EIS and CV experiments. It also shows the AFM image of the surface before and after modification.

\section{ToC Graphic.}

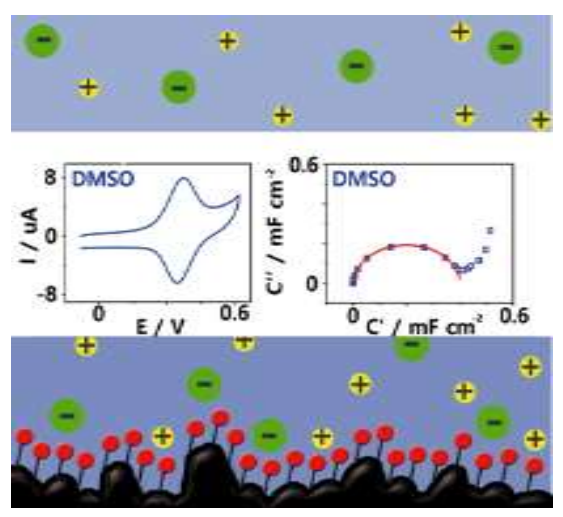

\section{Text for the Table of Contents}

Electrochemical properties of functionalized carbons with a nanostructured ferrocene alkyl monolayer were evaluated with different electrolytes and solvents for charge storage applications. 


\section{KEYWORDS}

Carbon Surface Modifications, Diazonium Salts, Electrografting, Nano-structuration, Pseudo-Supercapacitor.

\section{REFERENCES}

[1] B. E. Conway (1999) Electrochemical supercapacitors. Scientific fundamentals and technological applications; Kluwer Academic Plenum Publishers, New York.

[2] P. L. Taberna, P. Simon, J. -F. Fauvarque, J. Electrochem. Soc. 2003, 150, 292-300.

[3] M. Toupin, D. Belanger, I. R. Hill, D. Quinn, J. Power Sources 2005, 140, 203-210.

[4] P. Simon, Y. Gogotsi, Nat. Mater. 2008, 7, 845-854.

[5] J. Segalini, B. Daffos, P. L. Taberna, Y. Gogotsi, P. Simon, Electrochim. Acta 2010, $55,7489-7494$.

[6] M. Delamar, R. Hitmi, J. Pinson, J. -M. Savéant, J. Am. Chem. Soc. 1992, 114, 58835884 .

[7] J. Pinson, F. Podvorica, Chem. Soc. Rev. 2005, 34, 429-439.

[8] D. Bélanger, J. Pinson, Chem. Soc. Rev. 2011, 40, 3995-4048.

[9] K. Kalinathan, D. P. Desroches, X. Liu, P. G. Pickup, J. Power Sources 2008, 181, $182-185$.

[10] G. Pognon, T. Brousse, L. Demarconnay, D. Bélanger, J. Power Sources 2011, 196, 4117-4122.

[11] G. Wang, L. Zhang, J. Zhang, Chem. Soc. Rev. 2012, 41, 797-828.

[12] T. Brousse, D. Belanger, J. W. Long, J. Electrochem. Soc. 2015, 162, A5185-A5189.

[13] D. M. Anjos, J. K. McDonough, E. Perre, G. M. Brown, S. H. Overbury, Y. Gogotsi, V. Presser, Nano Energy 2013, 2, 702-712.

[14] X. Chen, H. Wang, H. Yi, X. Wang, J. Phys. Chem. C 2014, 118, 8262-8270.

[15] A. Le Comte, D. Chhin, A. Gagnon, R. Retoux, T. Brousse, D. Belanger, J. Mater. Chem. A 2015, 3, 6146-6156.

[16] T. Brousse, C. Cougnon, D. Bélanger, J. Braz. Chem. Soc. 2018, 29, 989-997.

[17] C. Cougnon, E. Lebègue, G. Pognon, J. Power Sources 2015, 274, 551-559.

[18] G. Ma, F. Hua, F. Sun, E. Feng, Z. Zhang, H. Peng, Z. Lei, Ionics 2018, 24, 549-561.

[19] E. Touzé, F. Gohier, B. Daffos, P. -L. Taberna, C. Cougnon, Electrochim. Acta 2018, 265, 121-130.

[20] G. Pognon, T. Brousse, D. Bélanger Carbon 2011, 49, 1340-1348.

[21] Y. R. Leroux, F. Hui, J. -M. Noël, C. Roux, A. J. Downard, P. Hapiot, Langmuir 2011, 27, 11222-11228.

[22] Y. R. Leroux, H. Fei, J.-M. Noël, C. Roux, P. Hapiot, J. Am. Chem. Soc. 2010, 132, 14039-14041. 
[23] P. Hapiot, C. Lagrost, Y. R. Leroux, Curr. Opin. Electrochem. 2018, 7, 103-108.

[24] Y. R. Leroux, P. Hapiot, Chem. Mater. 2013, 25, 489-495.

[25] E. Laviron, J. Electroanal. Chem. 1984, 164, 213-227.

[26] D. Evrard, F. Lambert, C. Policar, V. Balland, B. Limoges, Chem. Eur. J. 2008, 14, 9286-9291.

[27] A. L. Eckermann, D. J. Feld, J. A. Shaw, T. J. Meade, Coord Chem Rev. 2010, 254, 1769-1802.

[28] J. M. Casas-Solvas, A. Vargas-Berenguel, L. F. Capitán-Vallvey, F. SantoyoGonzález, Org. Lett. 2004, 6, 3687-3690.

[29] J. Savéant (2006) Elements of Molecular and Biomolecular Electrochemistry: An Electrochemical Approach to Electron Transfer Chemistry; John Wiley \& Sons Inc., Ed.; Hoboken, New Jersey.

[30] E. Barsoukov, J. R. Macdonald (2015) Impedance Spectroscopy: Theory, Experiments and Applications; John Wiley \& Sons Inc., Hoboken, New Jersey.

[31] J. P. Randin, E. Yeager, J. Electroanal. Chem. 1975, 58, 313-322.

[32] P. R. Bueno, G. Mizzon, J. J. Davis, J. Phys. Chem. B 2012, 116, 8822-8829.

[33] S. Evans, J. Electrochem. Soc. 1966, 113, 165-168.

[34] C. Amatore, E. Maisonhaute, B. Schöllhorn, J. Wadhawan, ChemPhysChem 2007, 8, 1321-1329.

[35] Q. -W. Sun, K. Murase, T. Ichii, H. Sugimura, ECS Trans. 2009, 16, 575-581.

[36] Q. -W. Sun, K. Murase, T. Ichii, H. Sugimura, J. Electroanal. Chem. 2010, 643, 5866. 